\title{
Significance of factors contributing to surgical complications and to late outcome after elective surgery of cerebral arteriovenous malformations
}

\author{
Carlo Schaller, Johannes Schramm, Dorothee Haun
}

\begin{abstract}
Objectives-This study focuses on the relevance of size, eloquence, type of venous drainage, the Spetzler-Martin scale as a whole, and other factors, such as rupture of cerebral arteriovenous malformations (AVMs) for the prediction of neurological deficits in the context of microsurgical AVM removal.
\end{abstract}

Methods-One hundred and fifty patients with AVMs, whose data were retrieved from a prospectively employed computerised data bank were included. Seventeen patients $(11.3 \%)$ underwent preoperative embolisation. According to the SpetzlerMartin scale they were graded as follows: $22.0 \%$ grade I, $32.0 \%$ grade II, $29.3 \%$ grade III, $14.0 \%$ grade IV, and $2.7 \%$ grade V. Intracerebral haemorrhage was present in $39.0 \%$. The AVMs were $<3 \mathrm{~cm}$ in $52.0 \%$, $3-6 \mathrm{~cm}$ in $43.3 \%$ and $>6 \mathrm{~cm}$ in $4.7 \% ; 59.3 \%$ of the AVMs were eloquently located and $29.3 \%$ had deep venous drainage (DVD). Follow up information was assessed 6 months after surgery in all but one patient, who died. The applied statistical test was $\chi^{2}$.

Results-Surgical morbidity was $15.3 \%$. Early new deficits were noted in $39.3 \%$, permanent new deficits in $10.6 \%$, being significant (major) in $7.3 \%$. The ocurrence of permanent deficits correlated significantly with size, deep venous drainage, and the Spetzler-Martin scale. There was statistical evidence for a trend in risk of poor surgical outcome across the three categories non-eloquent, "less eloquent" (for example, visual cortex) and "highly eloquent" (brainstem, basal ganglia, or precentral cortex) with the last being associated with the highest risk for permanent neurological compromise.

Conclusion "Eloquence" of the SpetzlerMartin scale should be divided into "highly eloquent" and "less eloquent", which is important for risk analysis of the treatment of asymptomatic and deep seated AVMs and for future trials comparing various treatment modalities. In addition, resection of eloquent AVMs $v$ noneloquent ones is significantly associated with higher surgical morbidity. (F Neurol Neurosurg Psychiatry 1998;65:547-554)

Keywords: arteriovenous malformation: grading: surgical risk
As for the grading of intracranial arteriovenous malformations (AVMs) the scale according to Spetzler and Martin has found widespread acceptance among the neurosurgical community. ${ }^{1}$ Their grading system is based on AVM size (<3 $v 3-6 v>6 \mathrm{~cm}$ ), eloquence of localisation (yes $v$ no) and type of venous drainage (superficial $v$ deep) and studies exist on the usefulness of this or of other scales in terms of operative risk, long term outcome, and other variables. ${ }^{1-6}$ In a previous study from Erlangen, several grading systems were compared, but the number of patients was still small $(n=48)$ and they were operated on by various surgeons ${ }^{6}$; nevertheless the value of the Spetzler-Martin scale was confirmed. In 1996 the team at the Barrow Neurological Institute published their statistically calculated results with prospective application of the SpetzlerMartin scale and came to the conclusion that this scale is indeed sufficient for determination of the surgical risk and the associated ocurrence of new neurological deficits as well as long term outcome. ${ }^{2}$ Their study, however, did not include other factors of interest, such as the preoperative psychosocial status of the patient, presence versus absence of symptomatic intracerebral haemorrhage, and treatment associated surgical morbidity. Therefore we have analysed our prospectively computerised AVM data bank of the personal surgical series of the senior author with respect to these factors. The intention was to assist future decision processes on the operability of cerebral AVMs, especially eloquently located ones, and to shed light on the presently available technical standards.

\section{Patients and methods}

PATIENT CHARACTERISTICS

A computerised data bank system consisting of 128 items, implemented in 1985, provided the information on patients' age, sex, size, neurological status, and follow up, including Karnofsky scores, as well as the AVMs' location, grading, and anatomical and radiological features (table 1). ${ }^{7}$

One hundred and fifty patients -75 females and 75 males-who were operated on for intracerebral AVMs in a 13 year period between January 1983 and December 1995 by the senior author (JS) were included in the study. Age ranged from 6 to 72 (mean 34.5) years. One patient, a 43 year old woman, had two AVMs - a centrally located one and an occipital one-and was thus included twice as two separate patients.

In addition we split from the group of 89 with eloquently located AVMs, a subgroup 
Table 1 Patients and characterstics

\begin{tabular}{|c|c|c|c|c|}
\hline \multirow{3}{*}{ Age } & Range (y) & Mean (SD) & \multicolumn{2}{|l|}{ Median (y) } \\
\hline & $5-72$ & $34.5(14.7)$ & \multicolumn{2}{|l|}{32.5} \\
\hline & \multicolumn{2}{|l|}{ Number } & \multicolumn{2}{|l|}{ Percentage } \\
\hline \multicolumn{5}{|l|}{ Sex: } \\
\hline Female & 75 & & 50.0 & \\
\hline Male & 75 & & 50.0 & \\
\hline \multicolumn{5}{|l|}{ Size of AVM: } \\
\hline$<3 \mathrm{~cm}$ & 78 & & 52.0 & \\
\hline $3-6 \mathrm{~cm}$ & 65 & & 43.3 & \\
\hline$>6 \mathrm{~cm}$ & 7 & & 4.7 & \\
\hline \multicolumn{5}{|l|}{ Eloquence of AVM: } \\
\hline No & 61 & & 40.7 & \\
\hline Yes & 89 & & 59.3 & \\
\hline Highly eloquent & 15 & & 10.0 & \\
\hline \multicolumn{5}{|l|}{ Type of venous drainage: } \\
\hline Superficial & 106 & & 70.7 & \\
\hline Deep & 44 & & 29.3 & \\
\hline \multicolumn{5}{|l|}{ Spetzler-Martin grade: } \\
\hline I & 33 & & 22.0 & \\
\hline II & 48 & & 32.0 & \\
\hline III & 44 & & 29.3 & \\
\hline IV & 21 & & 14.0 & \\
\hline $\mathrm{V}$ & 4 & & 2.7 & \\
\hline \multicolumn{5}{|l|}{ Intracerebral haemorrhage: } \\
\hline No & 91 & & 60.7 & \\
\hline Yes & 59 & & 39.3 & \\
\hline \multicolumn{5}{|l|}{ Surgical morbidity: } \\
\hline No & 127 & & 84.7 & \\
\hline Yes & 23 & & 15.3 & \\
\hline \multicolumn{5}{|l|}{ Early neurological worsening during hospital stay: } \\
\hline No & 91 & & 60.7 & \\
\hline \multirow{2}{*}{\multicolumn{5}{|c|}{ Permanent (new) deficit within first 6 months: }} \\
\hline & & & & \\
\hline No & 129 & & 86.0 & \\
\hline Non-significant & 10 & & 6.7 & \\
\hline Significant & 11 & & 7.3 & \\
\hline Mortality within first 6 months & 1 & & 0.7 & \\
\hline Karnofsky pre-op/follow up at 6 months (FU6): & Pre-op (n) & $F U 6(n)$ & Pre-op $(\%)$ & $F U 6(\%)$ \\
\hline 10 & 4 & 0 & 2.7 & 0.0 \\
\hline 20 & 8 & 1 & 5.3 & 0.7 \\
\hline 30 & 16 & 3 & 10.7 & 2.0 \\
\hline 40 & 9 & 2 & 6.0 & 1.3 \\
\hline 50 & 4 & 5 & 2.7 & 3.4 \\
\hline 60 & 8 & 4 & 5.3 & 2.7 \\
\hline 70 & 10 & 20 & 6.7 & 13.4 \\
\hline 80 & 10 & 14 & 6.7 & 9.4 \\
\hline 90 & 39 & 42 & 26.0 & 28.2 \\
\hline 100 & 42 & 58 & 28.0 & 38.9 \\
\hline
\end{tabular}

consisting of 15 patients with highly eloquent AVMs. This subgroup included only pure precentral AVMs in nine patients and AVMs located in the basal ganglia in four and the brainstem in two patients.

In 17 of the patients endovascular embolisation was attempted previously. In none of them did this lead to permanent AVM occlusion. Thus the angioarchitectural data refer to the final preoperative angiographical status as encountered in our department. Due to restructure of the department we have recently adopted a more deliberate interventional neuroradiological approach.

In one patient with a left temporal AVM, proton beam therapy had been attempted previously. This had not changed the angiographical appearance of the AVM and thus he underwent surgical removal of the lesion. Twelve patients had additional cerebral aneurysms, partly related to AVM feeding arteries, partly in other arterial distributions. These aneurysms were either treated at the time of AVM removal if conveniently approachable, or in a separate surgical intervention.

One patient had an associated venous angioma and had a complicated postoperative course and was published as a case report in $1995 .^{8}$ Some of the patients with small AVMs have been the subject of a previous report focusing on the various treatment modalities. ${ }^{9}$
Table 1 presents detailed data on the patients.

\section{SURGICAL MANAGEMENT AND OUTCOME} MEASURES

As it is our surgical policy to perform AVM surgery on an elective basis, we have waited for clinical improvement in those severely impaired patients who were admitted to our intensive care unit with intracranial haemorrhage. Standard microsurgical techniques were applied for AVM dissection and removal under general anaesthesia. If considered necessary, urapidil was given intravenously to induce arterial hypotension. Neurophysiological monitoring or motor strip localisation by phase reversal and total intravenous anaesthesia was performed if considered helpful on certain occasions as in centrally located AVMs. Postoperatively the patients were extubated as soon as possible, followed by intensive care monitoring, and usually they were transferred to the general ward the next day.

Neurological examinations were performed on a daily basis during the patient's hospital stay with particular attention given to worsening of already pre-existing neurological deficits and development of new postoperative deficits. In all but one patient, who died on postoperative day 8 , follow up information was obtained after 3 and after 6 months-either by direct 
Table 2 Development of early new postoperative deficits (within first postoperative week)

\begin{tabular}{|c|c|c|}
\hline Preoperative characteristics & $\begin{array}{l}\text { Early new postoperative } \\
\text { deficit }(\%)\end{array}$ & $p$ Value \\
\hline \multicolumn{3}{|l|}{ Intracerebral haemorrhage $(\%)$ : } \\
\hline Absent $(\mathrm{n}=91)$ & 47.3 & \\
\hline Present $(n=59)$ & 27.1 & 0.0025 \\
\hline \multicolumn{3}{|l|}{ Size of AVM: } \\
\hline Small AVMs $<3 \mathrm{~cm}(\mathrm{n}=78)$ & 28.2 & \\
\hline AVMs $3-6 \mathrm{~cm}(\mathrm{n}=65)$ & 47.3 & \\
\hline Large AVMs $>6 \mathrm{~cm}(\mathrm{n}=7)$ & 85.7 & 0.01 \\
\hline \multicolumn{3}{|l|}{ Eloquence of AVM: } \\
\hline Non-eloquent $(n=61)$ & 18.0 & \\
\hline Less eloquent $(n=74)$ & 50.1 & \\
\hline Highly eloquent $(n=15)$ & 73.3 & 0.001 \\
\hline \multicolumn{3}{|l|}{ Deep venous drainage: } \\
\hline Superficial $(n=106)$ & 34.6 & \\
\hline Deep $(n=44)$ & 52.3 & 0.05 \\
\hline \multicolumn{3}{|l|}{ Spetzler-Martin grade: } \\
\hline $\mathrm{I}(\mathrm{n}=33)$ & 15.2 & \\
\hline II $(\mathrm{n}=48)$ & 25.3 & \\
\hline III $(n=44)$ & 56.4 & \\
\hline IV $(n=21)$ & 56.5 & \\
\hline$V(n=4)$ & 100.0 & 0.001 \\
\hline \multicolumn{3}{|l|}{ Karnofsky score: } \\
\hline $10-70(\mathrm{n}=59)$ & 39.0 & \\
\hline $80-100(n=91)$ & 39.6 & NS \\
\hline
\end{tabular}

evaluation in our outpatient ward or by letters from the referring physicians or rehabilitation centres. This included neurological assessment with differentiation between significant (major) and non-significant (minor) neurological deficits, respectively and assessment of the actual Karnofsky score. Minimal paresis of strength grade $4 / 5$, slight hemisensory findings, and small visual field cuts were rated minor deficits. Paresis of strength grade $3 / 5$ or worse and/or aphasia, acalculia, severe hemisensory deficits, and disabling visual field cuts were rated as major neurological deficits.

All patients underwent control angiography during their hospital stay within a maximum of 4 weeks postoperatively.

STATISTICAL TESTS

The influence on early new postoperative deficits, permanent neurological deficits, and surgical morbidity was calculated. The variables taken into account were size of the AVM, eloquence, type of venous drainage, intracerebral haemorrhage, the Spetzler-Martin scale, and the Karnofsky score, which were all made available by a computerised database established at our institution.

As all outcome variables are dichotomous we have used the $\chi^{2}$ test as an appropriate test for all predictors. Statistical tests were performed by a qualified basic scientist (DH).

\section{Results}

GENERAL

One patient with a deep cerebellar AVM $4 \mathrm{~cm}$ in diameter died on postoperative day 8 , thus accounting for a mortality rate of $0.7 \%$ in the whole series. On uneventful extubation and awakening she deteriorated during the night after surgery, angiography disclosed no residual AVM, and on cranial CT there was neither evidence of rebleeding nor of excessive swelling. Local microsurgical revision and inspection did not disclose any obvious reason for her clinical deterioration and consecutive herniation.

Another patient with a dorsal thalamic AVM had early rebleeding from an obviously incom- pletely removed AVM nidus. He made a poor recovery after reoperation with persisting aphasia and severe spastic hemiparesis. Thus the overall AVM exclusion rate as controlled with angiography was $99.3 \%$ including a patient who underwent planned staged resection of a very large right frontal AVM.

Surgical morbidity accounted for $15.3 \%$ (23 cases) and included subgaleal CSF collection (three cases), meningitic hydrocephalus (two cases), haematotympanon (two cases), osteomyelitis of the bone flap (two cases), hydrocephalus (two cases), subdural hygroma (two cases), pulmonary embolism (one case), urinary tract infection (one case), meningitis (one case), acute respiratory distress syndrome (one case), gastric ulcer bleeding (one case), pneumonia (one case), wound infection (one case), brain retraction related oedema (one case), venous bleeding (one case), and mandibular joint dysfunction (one case).

Fifty nine patients $(39.9 \%)$ developed early new neurological deficits or worsening of pre-existing neurological deficits during their hospital stay. On late follow up, 6 months postoperatively, 21 patients $(14.0 \%)$ had neurological deficits-either new ones or worsened pre-existing ones. Of these, 10 patients $(6.7 \%)$ had minor deficits according to our classification, and 11 patients $(7.3 \%)$ had major deficits. Five out of these 21 patients had improved compared with their preoperative neurological status, thus leading to a total of 16 $(10.7 \%)$ surgically induced permanent neurological deficits. Therefore, 134 patients were symptom free or had at least reached their best preoperative status.

According to the Karnofsky score of the remaining 149 patients at follow up (table 1), $114(76.0 \%)$ were functioning independently or with only minimal assistance from their environment (scores 80-100), whereas 11 $(7.3 \%)$ still had severe impairment of consciousness and severly impaired neurological status (scores 10--50).

\section{EARLY POSTOPERATIVE DEFICITS}

Patients without preoperative intracranial haemorrhage were more likely to develop new neurological deficits than those with preoperative intracranial haemorrhage (table 2). The size of the AVM was also significantly associated with development of early neurological worsening. Eloquence of AVM localisation and deep venous drainage were also significantly correlated with early postoperative worsening. "Highly eloquent" AVMs were related to early postoperative worsening at a rate of $73.3 \%$ compared with $50.1 \%$ of "less eloquent AVMs". This difference is also significant. Increasing grade on the SpetzlerMartin scale also correlated with early postoperative worsening. Only five $(15.2 \%)$ patients with Spetzler-Martin scale grade I showed postoperative worsening compared with 13 $(61.9 \%)$ of the grade IV patients. The preoperative Karnofsky score (grouped into 10-70 and 80-100) showed no significant correlation with the percentage of early postoperative worsening. 
Table 3 Permanent neurological deficits (major plus minor deficits)

\begin{tabular}{|c|c|c|}
\hline Preoperative characteristics & $\begin{array}{l}\text { Permanent neurological deficits } \\
\text { (major plus minor) (\%) }\end{array}$ & $p$ Value \\
\hline \multicolumn{3}{|l|}{ Intracerebral haemorrhage: } \\
\hline Absent $(n=91)$ & 15.4 & \\
\hline Present $(n=59)$ & 11.9 & NS \\
\hline \multicolumn{3}{|l|}{ Size of AVM: } \\
\hline Small AVMs $<3 \mathrm{~cm}(\mathrm{n}=78)$ & 5.1 & \\
\hline AVMs $3-6 \mathrm{~cm}(n=65)$ & 21.5 & \\
\hline Large AVMs $>6 \mathrm{~cm}(\mathrm{n}=7)$ & 42.9 & 0.01 \\
\hline \multicolumn{3}{|l|}{ Eloquence of AVM: } \\
\hline Non-eloquent $(\mathrm{n}=61)$ & 3.3 & \\
\hline Less eloquent $(\mathrm{n}=74)$ & 17.6 & \\
\hline Highly eloquent $(n=15)$ & 40.0 & 0.01 \\
\hline \multicolumn{3}{|l|}{ Deep venous drainage: } \\
\hline Superficial $(n=106)$ & 29.5 & \\
\hline Deep $(n=44)$ & 7.5 & 0.01 \\
\hline \multicolumn{3}{|c|}{ Spetzler-Martin grade (minor (major)): } \\
\hline$I(n=33)$ & $0.0(3.0)$ & \\
\hline II $(\mathrm{n}=48)$ & $0.0(0.0)$ & \\
\hline III $(n=44)$ & $15.9(6.8)$ & \\
\hline IV $(n=21)$ & $9.5(28.6)$ & \\
\hline$V(n=4)$ & $25.0(25.0)$ & 0.05 \\
\hline \multicolumn{3}{|l|}{ Karnofsky score: } \\
\hline $10-70(\mathrm{n}=59)$ & 13.8 & \\
\hline $80-100(\mathrm{n}=91)$ & 14.3 & NS \\
\hline
\end{tabular}

LATE NEUROLOGICAL OUTCOME

Neither absence nor presence of intracranial haemorrhage were statistically correlated with permanently lasting new neurological deficits (table 3 ). Increasing size was significantly correlated with permanent deficits in the $\chi^{2}$ test. The difference between development of permanent neurological deficits as related to noneloquence and eloquence according to the Spetzler-Martin scale reached significance.

Significance for the development of permanent neurological deficits was also reached with subdivision of eloquence into "less eloquent" and"highly eloquent" lesions. Thus with establishment of the subgroup of 15 patients with highly eloquent lesions, of which three $(20.0 \%)$ had permanent minor and another three $(20.0 \%)$ had permanent major deficits, 74 patients with "less eloquent AVMs remained. Of these seven $(9.5 \%)$ had permanent minor and six $(8.1 \%)$ had major deficits.

The presence of deep venous drainage with regard to permanent neurological impairment reached significance when compared with superficial drainage.

Table 4 Surgical morbidity

\begin{tabular}{|c|c|c|}
\hline Preoperative characteristics & Surgical morbidity (\%) & $p$ Value \\
\hline \multicolumn{3}{|l|}{ Intracerebral haemorrhage: } \\
\hline Absent $(n=91)$ & 18.7 & \\
\hline Present $(n=59)$ & 10.2 & 0.01 \\
\hline \multicolumn{3}{|l|}{ Size of AVM: } \\
\hline Small AVMs $<3 \mathrm{~cm}(\mathrm{n}=78)$ & 11.5 & \\
\hline AVMs 3-6 cm $(\mathrm{n}=65)$ & 18.5 & \\
\hline Large AVMs $>6 \mathrm{~cm}(\mathrm{n}=7)$ & 28.6 & NS \\
\hline \multicolumn{3}{|l|}{ Eloquence of AVM: } \\
\hline Non-eloquent $(n=61)$ & 8.2 & $\mathrm{p}=0.05$ Non-eloquent $v$ \\
\hline Less eloquent $(\mathrm{n}=74)$ & 20.3 & eloquent, NS less $v$ highly \\
\hline Highly eloquent $(n=15)$ & 20.0 & eloquent \\
\hline \multicolumn{3}{|l|}{ Deep venous drainage: } \\
\hline Superficial $(\mathrm{n}=106)$ & 15.9 & \\
\hline Deep $(n=44)$ & 15.1 & NS \\
\hline \multicolumn{3}{|l|}{ Spetzler-Martin grade: } \\
\hline$I(n=33)$ & 9.1 & \\
\hline II $(n=48)$ & 8.3 & \\
\hline III $(n=44)$ & 25.0 & \\
\hline IV $(n=21)$ & 23.8 & \\
\hline$V(n=4)$ & 0.0 & NS \\
\hline \multicolumn{3}{|l|}{ Karnofsky score: } \\
\hline $10-70(\mathrm{n}=59)$ & 13.8 & \\
\hline $80-100(n=91)$ & 14.3 & NS \\
\hline
\end{tabular}

The Spetzler-Martin scale as a whole correlated well with the occurrence of new permanently lasting deficits (table 3).

The preoperative Karnofsky score was not relevant for the development of permanently lasting postoperative deficits.

It is important to note that of these 21 patients with permanent minor and major deficits 16 had deteriorated with surgery and five had improved from a preoperatively bad status to a "better" one-yet with permanent deficits. Thus surgically induced permanent deficits (major plus minor) accounted for $10.6 \%$ of the whole study population, being significant or major in $7.3 \%$.

\section{SURGICAL MORBIDITY}

The correlation between absence of preoperative intracranial haemorrhage and occurrence of surgical morbidity reached significance (table 4). Size was not correlated with the occurrence of surgical morbidity, whereas eloquence of the AVM location was. Neither the type of venous drainage nor the preoperative Karnofsky score showed statistically relevant correlation with surgical morbidity. The Spetzler-Martin scale itself did not reach significance when correlated with surgical morbidity.

KARNOFSKY SCORE ON LATE FOLLOW UP

Only the preoperative Karnofsky score showed a significant correlation with the Karnofsky score 6 months after surgery. When grouped into moderate and poor preoperative Karnofsky scores (10-70) and good scores (80-100) as related to long term neurological outcome no correlation was found.

Neither size, nor eloquence, type of venous drainage, or presence or absence of intracranial haemorrhage showed correlations.

\section{Discussion}

GRADING AND OUTCOME

The treatment of intracerebral AVMs still poses a formidable challenge to the neurosurgeon. Part of the strategy comprises evaluation of the operative risk compared with the expected outcome from surgical removal of the AVM, and decision analysis, which has to include alternative or combined treatment such as radiosurgery or embolisation therapy. Therefore, several factors have to be included in the pretreatment analysis, part of which are the clinical presentation and the status of the patient, age, expected natural course of the AVM and others. To make things easier, various grading systems, including a tool for decision analysis, have been developed, one of which - the Spetzler-Martin scale- has gained by far the highest degree of acceptance. ${ }^{13-610}$ This is mainly based on the simplicity of this scale, which refers to AVM size, eloquence, and type of venous drainage with a maximum of five points - and with six points indicating an unoperable AVM.

We were interested in the predictive value of the Spetzler-Martin scale as a whole, its individual factors, and in other potential factors contributing to late outcome after AVM 
surgery. Our case material was strictly prospectively collected and stored on a database system. As all patients were operated on by the same surgeon, this should provide a functioning tool for future analysis of the individual surgical risk.

Our results prove the reliability of the Spetzler-Martin scale as a whole for the assessment of the operative risk and the chance of persisting neurological deterioration after surgery. This is in concordance with the findings of a previous study of 120 patients, who were all operated on by Spetzler himself and reached significance. ${ }^{2}$ Their study group was comparable with ours with more than $50 \%$ of the AVM located in eloquent brain regions and different in that $63 \%$ of their series were rated grade I-III and $37 \%$ grade IV and V on the SpetzlerMartin scale, whereas $83 \%$ of our patients were grade I-III and only $17 \%$ grade IV and V.

An important finding is that in our series the rate of early postoperative neurological deterioration $(39.3 \%)$ - that is, during the first postoperative week - seems high compared with other studies. This may in part be due to the fact that our study design was indeed purely prospective and that even minor changes such as a slight motor drift or a small visual field deficit were assessed and rated as a deficit. Most of these deficits improved until follow up 6 months after surgery. This phenomenon of a high rate of early deficits compared with the rate of persisting deficits has also been described by other authors. ${ }^{2}{ }^{11} 12$ In Hamilton's and Spetzler's series of 120 patients early new neurological deficits accounted for 15\% (18 patients), but when splitting their population into grade I-III patients and grade IV/V patients, the rate of new deficits accounts for $2.6 \%$ in the first and for $36.4 \%$ in the second group. Neurological improvement from early to late follow up was noted in another eight $(18.2 \%)$ of their 44 grade IV/V patients. Their early deficits refer to assessment of neurological functioning six weeks postoperatively, however, and not to the first few days after surgery as in our study. Yasargil, in his personal series of 414 patients with AVMs of all sizes encountered 87 cases of neurological worsening compared with the preoperative status-patients with and without preoperative deficits together-thereby accounting for a rate of $21 \% .{ }^{12}$ For patients without preoperative deficits this rate increased to $40.5 \%$. Because occurrence of early neurological deterioration was significantly correlated with all investigated variables in our study - absence of intracranial haemorrhage, the Spetzler-Martin scale, size, eloquence, and drainage of the AVM-except for the preoperative Karnofsky score, no assumptions of essential practical value for presurgical risk analysis can be drawn from this fact.

The proportion of permanent deficits among our patient population-minor and major ones together-of $14 \%$ seems high compared with other large surgical series such as those of Hamilton and Spetzler or Yasargi. ${ }^{2}{ }^{12}$ However, treatment induced permanent deficits accounted for $10.7 \%$ only, as five out of the 21 patients had improved with surgery despite having permanent deficits. Yasargil reported 21 cases $(5.1 \%)$ of permanent deficits among his total series of 414 patients. ${ }^{12}$ However, it is not easy to compare these numbers exactly, as he had divided his measures of operative outcome into good $(81.9 \%)$, moderate $(12.8 \%)$, poor $(2.9 \%)$, and dead $(2.4 \%)$. Therefore, it is not clear how all 21 patients with postoperative neurological worsening were distributed among the groups with moderate and poor results and in how many this was due to surgery. In the series of Jomin et al an operative mortality of $12.5 \%$ was reported..$^{13}$ Early postoperative worsening occurred in another 30\% decreasing to $17 \%$ on late follow up. Their high mortality is explained by the fact that they have operated on comatose patients in $40 \%$ of cases. Their mortality in conscious patients accounted for $2 \%$ only. Shi et al in their study on the usefulness of their own grading scheme applied to a series of 100 patients reported $13 \%$ operative long term deficits (that is at least 3 months after surgery) and $1 \%$ operative mortality. ${ }^{5}$ The rate of deficits correlated with the grade of the AVMs according to their scale.

SIZE

That size is of importance for assessment of the surgical risk has been confirmed by various authors. ${ }^{12}{ }^{14}$ Pasqualin et al evaluated the AVM volume in their series and found an increasing volume (and eloquence of location) to be significantly associated with the ocurrence of neurological deficits. ${ }^{4}$ This was corroborated by the series of Morgan et al of 112 patients, in which only size - but neither age, sex, or neurological grade at the time of surgeryreached a significant predictive value for the operative risk..$^{15}$ In his study size was reduced to a two category predictor with AVMs $<4 \mathrm{~cm}$ and AVMs $>4 \mathrm{~cm}$. In our study we have split the AVMs into three categories, $<3 \mathrm{~cm}, 3-6 \mathrm{~cm}$, and $>6 \mathrm{~cm}$, as this is now common practice. Thereby, size reached significance in the $\chi^{2}$ test. The fairly optimistic view of Malik, who reported only two slight visual field deficits and "some difficulties in calculations" in another series of eight patients with very large AVMs (> $5 \mathrm{~cm}$ ) has to be interpreted with caution, because altogether this gives a morbidity rate of $3 / 8$ in that series. ${ }^{16}$ In the series of Batjer et al, of 62 patients, size did not reach significance as a predictor for worse outcome. ${ }^{17}$ This is of particular interest, as $\mathrm{AVMs}>6 \mathrm{~cm}$ represented $27 \%$ of their whole study population. But a trend toward better outcomes was apparent in their study with $95 \%$ of patients with AVMs $<3$ $\mathrm{cm}$ having good outcomes versus $65 \%$ of patients with AVMs $>6 \mathrm{~cm}$.

\section{LESS OR HIGHLY ELOQUENT VERSUS}

NON-ELOQUENT

In the series of Pasqualin et al comprising 248 patients, eloquence of AVM location did not reach significance for minor permanent deficits, but it did so for transient deficits, new major permanent deficits, and death in AVMs with a volume of less than $20 \mathrm{~cm}^{3}$. ${ }^{4}$ Their results with $33.1 \%$ transient new deficits 
remaining permanent $(6.9 \%$ minor and $2.8 \%$ major) with a mortality of $2.8 \%$ are comparable with ours.

In our study eloquence of AVM reached significance. There was statistical evidence for a trend in risk of poor surgical outcome across the three categories non-eloquent, "less eloquent" (postcentral, dominant temporal, occipital, corpus callosum), and "highly eloquent" (precentral, basal ganglia, and brainstem) with the last being associated with the highest risk for permanent neurological compromise.

This is the only index of the Spetzler-Martin scale that - in our opinion-deserves reconsideration, as the others (size and deep venous drainage) reached significance as potential predictors for neurological outcome. With increasing numbers of neurosurgeons treating AVMs of the basal ganglia, either microsurgically, radiosurgically, or as part of a combined regimen consisting of combinations of microsurgery, stereotactic irradiation, and superselective embolisation this has to be considered an important finding for decision analysis. In our 15 patients with highly eloquent AVMs the rate of early new deficits was $73.3 \%$ and that of permanent deficits $40.4 \%$, whereas in the less eloquent AVMs the rate of permanent deficits accounted for $17.6 \%$ only. This is comparable with other series of surgically removed AVMs of the basal ganglia or the brainstem with permanent deficits being reported in up to $50 \% .^{12}{ }^{18-21}$

All 22 patients in the study of Solomon and Stein returned to their premorbid state, but six had visual field deficits, three hemiparesis, two hemisensory loss, and one a Parinaud's syndrome, with only 18 AVMs being completely extirpated. ${ }^{22}$ Of the nine patients in their other series on surgical treatment of AVMs of the brainstem, who had all presented with haemorrhage, seven had returned to their premorbid status on late follow up. ${ }^{23}$ Kashiwagi et al suggested the surgical treatment of brainstem AVMs in cases of progressive character-that is, recurrent bleeding and progressive neurological worsening. ${ }^{19}$ Only the results of Yamada et al with their haemodynamically oriented resection of AVMs in functional areas $(0 \%$ mortality, only one patient out of 56 not returning to at least premorbid state) and those of Tew et al (13\% permanent deficits, $2 \%$ mortality, $9 \%$ rebleeding) are to be considered comparable with the results of surgery for less eloquent AVMs. ${ }^{24} 25$

One problem, however, in the interpretation of these results, is the difficulty in differentiating between persisting deficits and true new ones. This can be shown with the series of Hubschmann and Krieger, comprising 17 patients with AVMs located in "vital areas of the brain" including eight of the motor area and one of the internal capsule. ${ }^{26}$ They had encountered no new neurological deficits with surgery in their series. However, 16 of their patients had had intracranial or subarachnoid haemorrhage and five of these patients presented comatose or with plegia of one or two limbs. This may in part explain the excellent surgical results obtainable in patients with AVMs in vital brain areas, who are operated on in an already severely compromised neurological status. It is necessary to be aware of this potential bias when interpreting such studies.

\section{DEEP VENOUS DRAINAGE}

Deep venous drainage was related to permanent deficits in $29.5 \%$ versus $7.5 \%$ of AVMs with superficial venous drainage. This is in concordance with other studies. ${ }^{4}$ Pasqualin et al found the extent of the venous drainage system of greater importance for the development of postoperative haemodynamic complications than the presence of deep venous drainage. It is well known that eloquent AVM location close to the midline such as in basal ganglia AVMs is related to deep venous drainage. ${ }^{22}$ Therefore we think that these two factors are to be interpreted as functioning interdependently. Batjer et al found no difference in the rate of hyperaemic complications and poor late outcomes in patients with deep venous drainage compared with those with superficial drainage or both. ${ }^{17}$ That the venous side deserves special attention for pretreatment risk analysis was described by Miyasaka et al who found one draining vein, impaired venous drainage, and deep venous drainage being significantly associated with the AVMs' risk for haemorrhage. ${ }^{27} 28$

SURGICAL MORBIDITY

There was a significant correlation between the eloquence of the AVM localisation and surgical morbidity-20.2\% in patients with eloquent AVMs versus $8.2 \%$ in non-eloquent AVMs. This shows that in addition to the inherent risk of removal of an eloquently located AVM, these patients are at a higher risk of developing postoperative complications such as infection, hydrocephalus, deep vein or thrombosis. This may be due to the higher rate of neurological worsening encountered in this group, which most likely leads to delayed postoperative mobilisation and prolonged stay on intensive and intermediate care wards. This has not been explicitely reported by other groups and deserves attention during the phase of operative planning, and for the comparison with radiosurgical and embolisation series.

\section{NEUROSURGICAL DILEMMA}

The results presented and the statistical relevance of the subdivision of highly eloquent AVMs still leads to a true "surgical dilemma", which was already considered in part by Heros and Tu more than 10 years ago: "How to treat patients with unruptured AVMs?". ${ }^{29}$ At that time, however, the discussion was concerned whether there was an indication for surgical treatment of unruptured AVMs at all, as only few centres were involved in surgical treatment of cerebral AVMs and there were only a few larger series available from the literature. ${ }^{13}$ 29-31 The studies on the course of cerebral AVMs, most of which were published at that time and later have turned attention to a more aggressive treatment of these lesions, which is reflected by the literature of the past decade with efforts of specialists of various fields-neurosurgeons, 
neuroradiologists, and stereotactic radiotherapists-involved in the care of these patients. ${ }^{17} 30$ 32-40

The discussion of AVM treatment has now changed emphasis - regarding the question as "how to treat patients with unruptured highly eloquent AVMs". We advocate the microsurgical removal of small and medium sized AVMs in all areas, including the highly eloquent ones, as long as the patients have intracranial haemorrhage with consecutive neurological deficits, or if the small and medium sized lesions are located in uneloquent or less eloquent regions. Asymptomatic patients with small AVMs located in the premotor cortex, the basal ganglia, and the brainstem are referred to radiosurgical centres after having been informed about the inherent risks of radiosurgery, which cannot be considered a minimally invasive method, as side effects possibly occur years after radiation treatment and there is a prolonged risk of bleeding. ${ }^{89-46}$ Asymptomatic patients with medium sized AVMs in highly eloquent areas should possibly to be treated with a combined regimen of embolisation, microsurgery, and radiosurgery such as promoted by Lawton et $a l,{ }^{47}$ but despite their low morbidity rate of $11 \%$ it is necessary to be aware of the fact that only $72 \%$ of the AVMs were completely removed or obliterated and that nine of the lesions were $<3 \mathrm{~cm}$, nine from $3-6 \mathrm{~cm}$ and $14>6 \mathrm{~cm}$. That means that $28 \%$ of patients remained at risk for bleeding or rebleeding. In addition, this regimen requires a functioning true centre of excellence with all these subspecialised groups working together-logistically, seriously convinced, and honestly. In our series $11.3 \%$ of patients underwent embolisation for presurgical reduction of AVM size.

Patients with AVMs $>6 \mathrm{~cm}$ and/or with grades IV and V nearly always have eloquent regions involved, and the decision to operate or not has to be made on an individual basis, as the risk of postoperative worsening is high, if these patients have not already bled from AVM rupture, and as complete elimination of the AVM only meets the treatment goal with protection from future haemorrhage. The recently proposed risk table of Kondziolka et al, which is based on previous studies regarding the natural course of untreated AVMs, is of great value for assessment of the lifetime risk of haemorrhage if used as a decision tool in these patients. ${ }^{48}$ But the prognosis for these patients has not improved substantially-neither regarding surgical outcome nor with respect to the presently available combined treatment regimens. ${ }^{36} 47-49$

1 Spetzler RF, Martin NA. A proposed grading system for arteriovenous malformations. $\mathcal{F}$ Neurosurg 1986;65:476-83. 2 Hamilton MG, Spetzler RF. The prospective application of a grading system for arteriovenous malformations. Neurosurgery 1994;34:2-7.

3 Luessenhop AJ, Gennarelli TA. Anatomical grading of supratentorial arteriovenous malformations for determining operability. Neurosurgery 1977;1:30-5.

4 Pasqualin A, Barone G, Cioffi F, et al. The relevance of anatomic and hemodynamic factors to a classification of tomic and hemodynamic factors to a classification of 28:370-9.

5 Shi Y, Chen X. A proposed scheme for grading intracranial arteriovenous malformations. F Neurosurg 1986;65:484-9.
6 Steinmeier R, Schramm J, Müller H-G, et al. Evaluation of prognostic factors in cerebral arteriovenous malformations. prognostic factors in cerebral art
Neurosurgery 1989;24:193-200.

7 Karnofsky DA, Burchenal JH. The clinical evaluation of chemotherapy agents in cancer. In: Macleod CM, ed. Evaluation of chemotherapy agents. New York: Columbia University Press, 1949:191-204.

8 Meyer B, Stangl AP, Schramm J. Association of venous and true arteriovenous malformation: a rare entity among mixed vascular malformations of the brain. 7 Neurosurg 1995;83:141-4.

9 Schaller C, Schramm J. Microsurgical results in small AVMs accessible for radiosurgical or embolization treatment. Neurosurgery 1997;40:664-74.

10 Fisher WS: Decision analysis: a tool of the future: an application to unruptured arteriovenous malformations. Neurocation to unruptured arter.
surgery $1989 ; 24: 129-35$.

11 Heros RC, Korosue K, Deibold PM. Surgical excision of cerebral arteriovenous malformations: late results. Neurosurgery 1990;26:570-8.

12 Yasargil MG. Summary of operative results. In: MG Yasargil, ed. Microneurosurgery, Vol IIIb. AVM of the brain, clinical nonoperated cases, cavernous and venous angiomas, neuroanesthesia. Stuttgart, New York: Thieme, 1987:25083.

13 Jomin M, Lesoin F, Lozes G. Prognosis for arteriovenous malformations of the brain in adults based on 150 cases. Surg Neurol 1985;23:362-6.

14 Pertuiset B, Ancri D, Arthuis F, Siddiqui SA. Radical open surgery of supra-tentorial arteriovenous malformations. Proceedings of the International Symposium on Surgery for Cerebral Stroke, Sendai 1987. Tokyo: Springer, 1988:475-9.

15 Morgan MK, Johnston IH, Hallinan JM, Weber NC. Complications of surgery for arteriovenous malformations of the brain. F Neurosurg 1993;78:176-82.

16 Malik GM. Surgical treatment of large cerebral arteriovenous malformations. In: Smith RR, Haerer A, Russell WF, eds. Vascular malformations. New York: Raven Press, 1982:77-99.

17 Batjer HH, Devous MD, Siebert JB, et al. Intracranial arteriovenous malformations: relationship between clinical factors and surgical complications. Neurosurgery 1989;24:759.

18 Gomez-Tortosa E, Sychra JJ, Martin EM, et al. Postoperative cognitive and single photon emission computed tomography assessment of patients with resection of perioperative high-risk arteriovenous malformations. $\mathrm{Neu}$ rosurgery 1995;36:447-58.

19 Kashiwagi S, van Loveren HR, Tew JM, et al. Diagnosis and treatment of vascular brain-stem malformations. $\mathcal{F}$ Neurosurg 1990;72:27-34.

20 Malik GM, Umansky F, Patel S, et al. Microsurgical removal of arteriovenous malformations of the basal ganglia. Neuroof arteriovenous 1988;23:209-17.

21 Samii M, Bini W. Management of deep-seated cerebral AVMs. Report on 28 cases. In: Suzuki J, ed. Advances in surgery for cerebral stroke. Proceedings of the International Symposium on Surgery for Cerebral Stroke, Sendai 1987. Tokyo: Springer 1988:461-5.

22 Solomon RA, Stein BM. Interhemispheric approach for the surgical removal of thalamocaudate arteriovenous malformations. F Neurosurg 1987;66:345-51.

23 Solomon RA, Stein BM. Management of arteriovenous malformations of the brain stem. F Neurosurg 1986;64:85764.

24 Tew JM, Lewis AI, Reichert KW. Management strategies and surgical techniques for deep-seated supratentorial arteriovenous malformations. Neurosurgery 1995;36:106572 .

25 Yamada S, Brauer F, Knieriem DS. Direct approach to arteriovenous malformations in functional areas of the cerebral hemispheres. F Neurosurg 1990;72:418-25.

26 Hubschmann OR, Krieger AJ. The perivenous technique of resection of arteriovenous malformations from vital areas of the brain. Surg Neurol 1987;27:323-30.

27 Miyasaka Y, Yada K, Ohwada T, et al. An analysis of the venous drainage system as a factor in hemorrhage from arteriovenous malformations. F Neurosurg 1992;76:239-43.

28 Miyasaka Y, Kurata A, Tokiwa K, et al. Draining vein pressure increases and hemorrhage in patients with arteriovenous malformation. Stroke 1994;25:504-7.

29 Heros RC, Tu YK. Unruptured arteriovenous malformations: a dilemma in surgical decision-making. Clin Neurosurg 1985;33:187-236.

30 Luessenhop AJ, Rosa L. Cerebral arteriovenous malformations. Indications for and results of surgery, and the role of tions. Indications for and results of surgery, and the rol
intravascular techniques. $\mathcal{F}$ Neurosurg 1984;60:14-22.

31 Wilson CB, Sang H, Domingue J. Microsurgical treatment of intracranial vascular malformations. I Neurosurg 1979; $51: 446-54$.

32 Auger RG, Wiebers DO. Management of unruptured intracranial arteriovenous malformations: a decision analysis. Neurosurgery 1992;30:561-9.

33 Brown RD, Wiebers DO, Forbes GS, et al. The natural history of unruptured intracranial arteriovenous malformations. $\mathcal{F}$ Neurosurg 1988;68:352-7.

34 Brown RD, Wiebers DO, Forbes GS. Unruptured intracranial aneurysms and arteriovenous malformations: frequency of intracranial hemorrhage and relationship of quency of intracranial hemorrhage

35 Brown RD, Wiebers DO, Torner JC, et al. Frequency of intracranial hemorrhage as a presenting symptom and subtype analysis: a population-based study of intracranial vas- 
cular malformations in Olmsted County, Minnesota. $\mathcal{F}$ Neurosurg 1996;85:29-32.

36 Dawson RC, Tarr RW, Hecht ST, et al. Treatment of arteriovenous malformations of the brain with combined embolization and stereotactic radiosurgery: results after 1 and 2 years. AfNR Am 7 Neuroradiol 1991;11:857-64.

37 Friedman WA, Bova FJ, Mendenhall WM. Linear accelerator radiosurgery for arteriovenous malformations: the relationship of size to outcome. F Neurosurg 1995;82:180-9.

38 Ondra SL, Troupp, George ED, et al. The natural course of symptomatic arteriovenous malformations of the brain: a 24-year follow-up assessment. F Neurosurg 1990;73:387-91.

39 Pollock BE, Lunsford DL, Kondziolka D, et al. Patient outcomes after stereotactic radiosurgery for "operable" arteriovenous malformations. Neurosurgery 1994:35:1-8.

40 Sisti MB, Kader A, Stein BM. Microsurgery for 67 intracranial arteriovenous malformations less than $3 \mathrm{~cm}$ in diameter. F Neurosurg 1993;79:653-60.

41 Friedman WA, Blatt DL, Bova FJ, et al. The risk of hemorrhage after radiosurgery for arteriovenous malformations. $\mathcal{F}$

42 Heros RC, Korosue K. Radiation treatment of cerebral arteriovenous malformations. N Engl f Med 1990;323:127-9.
43 Kihlstrom L, Guo W-Y, Karlsson B, et al. Magnetic resonance imaging of obliterated arteriovenous malformations up to 23 years after radiosurgery. $f$ Neurosurg tions up to 23

44 Ogilvy CS. Radiation therapy for arteriovenous malformations: a review. Neurosurgery 1990;26:725-35.

45 Schwartz M, O'Brien P, Davey P, et al. Current status of radiosurgery for arteriovenous malformations. Can $\mathcal{f}$ Neurol Sci 1991;18:499-502.

46 Yamamoto M, Jimbo M, Hara M, et al. Gamma knife radiosurgery for arteriovenous malformations: long term follow up results focusing on complications occurring more than 5 years after irradiation. Neurosurgery 1996;38:906-14.

47 Lawton MT, Hamilton MG, Spetzler RF. Multimodality treatment of deep arteriovenous malformations: thalamus, basal ganglia, and brainstem. Neurosurgery 1995;37:29-36.

48 Kondzilk predictions for arteriovenous malformation hemorrhage. predictions for arteriovenous

49 Mathis JA, Barr JD, Horton JA, et al. The efficacy of particulate embolization combined with stereotactic radioparticulate embolization combined with stereotactic radio-
surgery for treatment of large arteriovenous malformations of the brain. AfNR Am $\mathcal{F}$ Neuroradiol 1995; 16:299-306.

\section{NEUROLOGICAL STAMP}

\section{Ivan Mikhailovich Sechenov (1829-1905)}

Sechenov, son of a nobleman and a peasant, was born in the village of Teplyi Stan, now the village of Sechenovo,Gorky Oblast, on 1 August 1929. He graduated from the Main Engineering School in St Petersburg in 1848 and the medical faculty of Moscow University in 1856. From his teacher's Sechenov received the best instruction that Russia could offer in basic and clinical sciences. Pavlov referred to him as the Father of Russian physiology and scientific psychology.

Sechenov found most medical men to be empiricists and was disappointed by them. After graduation from the University of Moscow School of Medicine he studied abroad with J Müller, E DuBois-Reymond, and E Hoppe-Sayler in Berlin, O Funke in Leipzig, $\mathrm{K}$ Ludwig in Vienna, and $\mathrm{H}$ Helmholtz in Heidelberg. Much of his early work was done in Claude Bernard's laboratory. While abroad Sechenov prepared his doctoral dissertation, Data for the Future Physiology of Alcoholic Intoxication. His interest in neuropathology and physiology of the higher centres grew from his circle of associates. On his return to Russia he was made Adjunct Professor of Physiology in the Military Medical Academy. He left this position as a sign of protest against the Academy's failure to confirm Metchnikoff as Professor. Sechenov later became Professor of Physiology in the Universities of Odessa, St Petersburg, and Moscow. His physiology laboratory was the centre not only for physiology but also for pharmacology, toxicology, and clinical medicine.

His chief scientific works, which appeared in the 1860 s, were devoted to the examination of respiration, and to the discovery of the inhibitory centres of the spinal reflexes in the medulla and cord. During experiments conducted on a frog in 1862, Sechenov noted that the reflex of the spinal cord (bending of the legs when a frog is immersed in a weak acid solution) was depressed on chemical or electrical stimulation of the thalamic region. The thalamic reflex inhibition centre was named Sechenov's centre (Setchenow's centre) and the phenomenon of central inhibition was named Sechenov's inhibition. His book Reflexes of the Brain (1863) achieved outstanding success. In this book he explained in physiological terms the psychological activities of humans and explained the entire behaviour of the human as being a complicated reflex act. His outline of conditioned reflexes later was expanded by his successor I

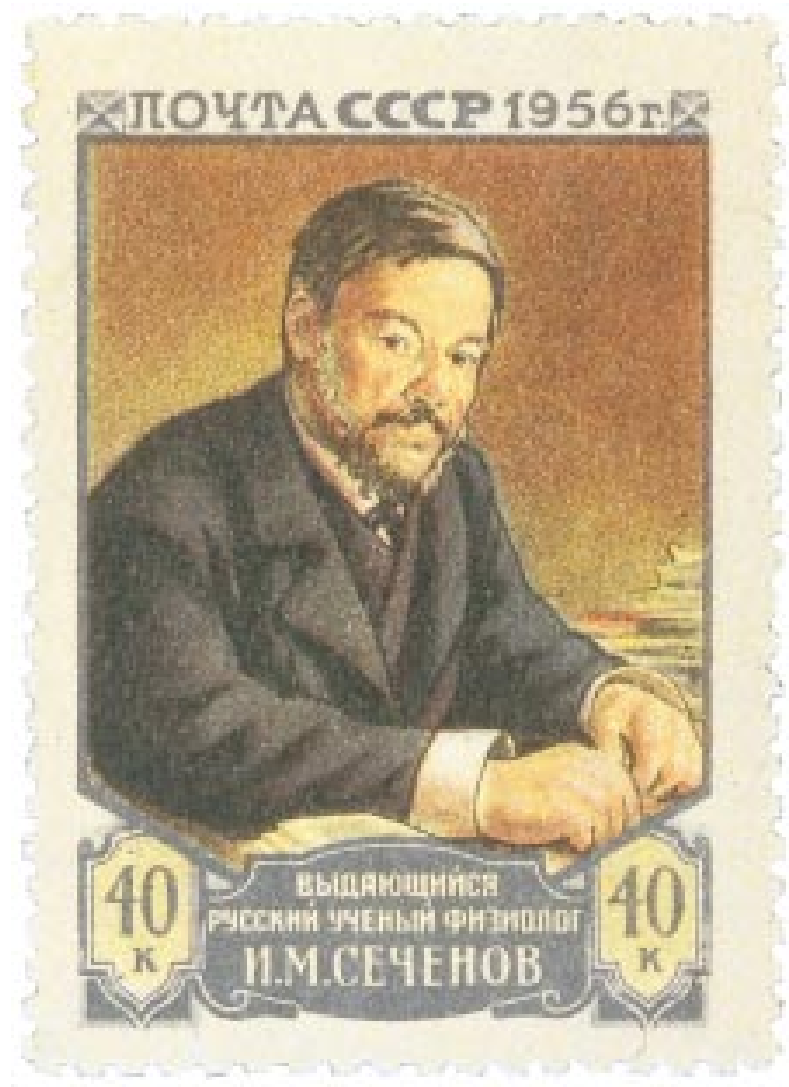

F Cyon. Cyon was in turn the teacher of Pavlov. Sechenov's protégé, Elie Metchnikoff, won the Nobel Prize in Medicine and Physiology in 1908. His wife Maria Alexandrovna Bulova became the first woman physician in Russia. He was honoured philatelically on 15 June 1956 on the foundation of the Institute of Development in Biochemical Physiology of the USSR Academy of Sciences. The portrait displayed was Sechenov at the age of 59 and was from an oil painting by Elias Yefimovich Repin (1840-1930), Professor of Painting at the St Petersburg Academy (Stanley Gibbons 611, Scott 1826).

L F HAAS 